\title{
Ketone Hydrosilylation with Sugar Silanes Followed by Intramolecular Aglycone Delivery: An Orthogonal Glycosylation Strategy
}

\author{
Zachary A. Buchan, Scott J. Bader, and John Montgomery \\ Department of Chemistry, University of Michigan, Ann Arbor, Ml 48109-1055, Fax: (+1) \\ 734-763-1106, Homepage: http://www.umich.edu/ jmgroup
}

Zachary A. Buchan: ; Scott J. Bader: ; John Montgomery: jmontg@umich.edu

\section{Keywords \\ $\mathrm{Ni}$; $\mathrm{Cu}$; hydrosilylation; glycosylation; chemoselectivity}

\begin{abstract}
Many classes of biomolecules derive their biological activity from the synergistic effects of carbohydrate and non-carbohydrate (aglycone) functionality.[1] From the standpoint of chemical synthesis, the assembly of the aglycone and attachment of a carbohydrate (glycosylation) are viewed as distinct operations. As a result, the independent synthesis of a suitably-protected aglycone and a suitably-protected carbohydrate is typically followed by a separate sequence involving Lewis acid activation of the sugar anomeric substituent and assembly of the $O$-glycoside bond via addition of a hydroxyl-bearing aglycone.[2] The powerful glycal oxidation method similarly involves addition of a hydroxyl nucleophile to the electrophilic anomeric position.[3] An important complement to these strategies involves intramolecular aglycone delivery.[4] Seminal work from Hindsgaul[5] and Ogawa[6] using acetal linkages and from Stork[7] and Bols[8] using silane linkages demonstrated that intramolecular aglycone delivery strategies provide a powerful entry to $c i s-1,2$ glycoside linkages, namely the synthetically challenging $\beta$-mannose and $\alpha$-glucose configurations. Whereas the intramolecular strategies involve glycoside bond assembly directly from an acetalor silyl-protected hydroxyl, preparation of the tethered aglycone-carbohydrate assembly is ultimately derived from a free hydroxyl on the aglycone earlier in the synthesis. An alternate strategy involving $O$-alkylation of a $\mathrm{C}-1-O$-hemiacetal nucleophile with an electrophilic aglycone provides a powerful entry to glycoconjugates and oligosaccharides, although this method also requires that potentially nucleophilic sites in the aglycone are protected.[9] As a complement to all of the above strategies, a glycosylation method that does not require a nucleophilic free hydroxyl on the aglycone at any point in the synthesis, and that tolerates spectator free hydroxyls on the aglycone, could have important implications as a strategy for native glycoside bond construction that is orthogonal to conventional glycosylation methods. [10]
\end{abstract}

With this challenge in mind, we were attracted to the notion of developing transition metalcatalyzed hydrosilylations of ketones by silyl hydride reagents that possess glycosyl donors as a silyl substituent. Such a strategy could allow site-selective installation of installing stereochemical features of the aglycone via reduction of the carbonyl. Herein we describe the

Correspondence to: John Montgomery, jmontg@umich.edu.

Supporting information for this article is available on the WWW under http://www.angewandte.org or from the author. 
efficient synthesis of "sugar silanes" to enable such a strategy, along with the first examples of the direct glycosylation of ketones as a fundamentally new and orthogonal strategy for preparing glycoside bonds.

Glycosyl donor reagents that possess a C-2 free hydroxyl, protecting groups at the 3, 4, and 6positions, and a thioalkyl anomeric substituent are readily prepared in the glucose or mannose configurations by known procedures.[11] The C-2 hydroxyl may be silylated in near quantitative yield using commercially available $\mathrm{Me}_{2} \mathrm{SiHCl}$ and $\mathrm{Et}_{3} \mathrm{~N}$ in dichloromethane to afford reagents $\mathbf{1}$ or $\mathbf{2}$ (Scheme 1). The synthesis of $\mathbf{1}$ or $\mathbf{2}$ may be performed on multigram scale, requiring only a single chromatographic purification. While $\mathbf{1}$ and $\mathbf{2}$ are not stable to chromatography, they are obtained in pure form and may be stored for months with comparable results in subsequent reactions compared with reagents that are freshly prepared.

In this intial study, we first examined ketone hydrosilylations with reagents $\mathbf{1 a}$ and $\mathbf{1 b}$ using either nickel[12] or copper[13] catalysts with IMes as the ligand, generated from 1,3dimesitylimidazolium chloride, and $\mathrm{KO}-t \mathrm{Bu}$ or $\mathrm{NaO}-t \mathrm{Bu}$. A variety of unhindered ketones underwent efficient couplings with the catalyst derived from $\mathrm{Ni}(\mathrm{COD})_{2}$ and IMes in THF, using $\mathrm{Ti}(\mathrm{O}-i \mathrm{Pr})_{4}$ as a Lewis acidic additive (Table 1) to afford hydrosilylation products 4 (starting from glucose) or $\mathbf{5}$ (starting from mannose). Control experiments demonstrated that no conversion was observed in the absence of the nickel catalyst. The procedure (Scheme 2) was generally effective with unhindered ketones, whereas the corresponding copper-IMes catalyst, generated in toluene following the procedure from Nolan,[13] was more effective with hindered ketones. Once substrates $\mathbf{4}$ or $\mathbf{5}$ were prepared via hydrosilylation, intramolecular glycosylation was carried out using $N$-iodosuccinimide and trimethylsilyltriflate with 2,6-di$t$-butyl-4-methylpyridine (2,6-DTBMP) in dichloromethane at -40 to $0{ }^{\circ} \mathrm{C}$ to produce $\alpha$ glucosides 6 (from 4) or $\beta$-mannosides 7 (from 5).[14] As described below, both ethylthio and phenylthio sugar silanes $\mathbf{1} \mathbf{a} / \mathbf{b}$ and $\mathbf{2} \mathbf{a} / \mathbf{b}$ were similarly effective in hydrosilylations, although the phenylthio donors were more effective in subsequent intramolecular glycosylations when hindered ketones were employed.

As a first example, coupling with benzyl acetone proceeded in high yield with the Ni(0)-IMes catalyst to afford a 54:46 mixture of diastereomers of $\mathbf{4 a}$ epimeric at the newly formed stereogenic center, thus illustrating that sugar chirality has little impact on the diastereoselectivity of the hydrosilylation (Table 1, entry 1 ). Glycosylation of $4 \mathbf{a}$ provided $\alpha$ glucoside 6a in $97 \%$ isolated yield with excellent diastereoselectivity at the anomeric position. Cyclic acetals and basic tertiary amines were tolerated in high yielding transformations with the $\mathrm{Ni}(0)$-IMes catalyst to produce $\mathbf{4 b}$ and $\mathbf{4 c}$ (entries 2-3), and glycosylation of these substrates afforded the $\alpha$-glucosides $\mathbf{6 b}$ and $\mathbf{6 c}$ in high yield and excellent diastereoselectivity.

Hydrosilylations of (-)-menthone (3d) were low yielding with the nickel catalyst system (ca. 20-25\% yield); however, the more reactive $\mathrm{Cu}$-IMes catalyst led to faster and higher yielding reactions (entry 4). Using either ethylthio or phenylthio sugar silanes $\mathbf{1 a}$ or $\mathbf{1 b}$, hydrosilylations using $\mathbf{3 d}$ were effective to produce $\mathbf{4 d}$ or $\mathbf{4 e}$ in good yield with 2:1 diastereoselectivity. Subsequent glycosylations, however, were much higher yielding with phenylthioglycosyl donor $\mathbf{4 e}$, which generated product $\mathbf{6 d}$ in $72 \%$ isolated yield, compared with $20 \%$ isolated yield from $\mathbf{4 d}$. The enhancement of diastereoselectivity observed in the glycosylation is derived from significantly different rates of glycosylation of the two diastereomers of $\mathbf{4 d}$ or $\mathbf{4 e}$. Efficiency of the process in $\beta$-mannosylations was next examined. Hydrosilylation of ketone $\mathbf{3 b}$ with mannose silane 2a was efficient with the Ni-IMes catalyst, affording product 5a in $86 \%$ isolated yield (entry 5). Glycosylation of $\mathbf{5 a}$ was moderately effective to generate exclusively the $\beta$-mannoside 7a in $58 \%$ isolated yield with excellent control of the anomeric stereochemistry. Hydrosilylation of (-)-menthone (3d) with mannose silane $\mathbf{2 b}$ using the $\mathbf{C u}$ IMes catalyst afforded $\mathbf{5 b}$ in $75 \%$ isolated yield with 2:1 diastereoselectivity (entry 6), and subsequent glycosylation afforded $\beta$-mannoside $\mathbf{7 b}$ in $74 \%$ isolated yield and excellent control 
of the anomeric configuration. Enhancement of the diastereomeric ratio derived from carbonyl reduction was again noted as described above (entry 4). These examples suggest that a broad range of ketones may be efficiently converted to either $\alpha$-glucosides or $\beta$-mannosides.[15,16]

As noted above, an important implication of a glycosylation procedure that does not require addition of a free hydroxyl on the aglycone to a glycosyl donor is its potential to allow site selective glycosylation of aglycones that possess unprotected hydroxyls.[17,18] Silanes are well known to undergo ketone hydrosilylations[13] and alcohol dehydrogenative silylations [19] with a broad range of transition metal catalysts, although remarkably little quantitative data is available regarding the relative rates of the two processes. Our initial examinations of the $\mathrm{Cu}$-IMes catalyst employed herein illustrated that addition of sugar silanes $\mathbf{1}$ and $\mathbf{2}$ are efficient with both ketones (hydrosilylation) and alcohols (dehydrogenative silylation), but generally fastest with unhindered hydroxyls. Alternatively, with the Ni-IMes catalyst, hydrosilylations of unhindered ketones proceed much more rapidly than dehydrogenative silylations of alcohols.[20]

In order to illustrate the opportunity for site-selective glycosylation of a hydroxy ketone, dihydrotestosterone (7) was subjected to the nickel-catalyzed hydrosilylation procedure, and only the ketone functionality was affected (Scheme 3). Starting with glucosilane 1a, silyl ether 8a was prepared in $89 \%$ isolated yield with 5:1 diastereoselectivity. Treatment of $\mathbf{8 a}$ to the conditions for intramolecular glycosylation afforded $\alpha$-glucoside 9a in $95 \%$ isolated yield with complete control of anomeric configuration. Purification of the products of intramolecular glycosylation involves treatment with $n \mathrm{Bu}_{4} \mathrm{NF}$, so any competitive silylation of the free hydroxyl by TMSOTf during the glycosylation event is inconsequential since the site selectivity is derived from the previous hydrosilylation event. Using the same hydroxyketone $\mathbf{7}$ combined with mannosilane 2a, efficient nickel-catalyzed site-selective hydrosilylation proceeds to generate product $\mathbf{8 b}$ in $80 \%$ isolated yield with 6:1 diastereoselectivity. As anticipated based on the lack of impact of sugar structure in controlling the hydrosilylation diastereoselectivity (Table 1, entry 1), diastereoselectivities involving hydrosilylation of chiral substrate 7 were comparable with both gluco- and mannosilanes 1a and 2a. Treatment of compound $\mathbf{8 b}$ to the glycosylation conditions afforded $\beta$-mannoside $\mathbf{9 b}$ in $92 \%$ isolated yield with complete control of anomeric stereochemistry.

Since the above example (Scheme 3) involves functionalization of an inherently biased substrate with a highly hindered free hydroxyl, we examined the site selectivity of a simpler substrate 10, which possess both an unhindered ketone and a primary hydroxyl. In this instance, we found highly complementary behavior of the nickel and copper catalytic systems. Treatment of 10 with glucosilane 1a using the Ni-IMes catalyst led to clean ketone hydrosilylation, affording product $\mathbf{1 1}$ in $86 \%$ isolated yield, whereas the corresponding reaction of $\mathbf{1 0}$ and $1 \mathbf{a}$ with the $\mathrm{Cu}$-IMes catalyst afforded product $\mathbf{1 2}$ from dehydrogenative silylation of the alcohol in $57 \%$ isolated yield, along with $7 \%$ yield of the bis-silylated product derived from reaction of both the ketone and alcohol. Products $\mathbf{1 1}$ and $\mathbf{1 2}$ were then converted to glycosides 13 and 14 by the standard procedure described above. This catalyst-controlled reversal of chemoselectivity in hydroxyketone functionalization with silanes is unprecedented to our knowledge.[21]

In summary, a new method has been developed that allows the conversion of ketones to native glycoside bonds without the intermediacy of free alcohols. Starting from a hydroxy ketone, the site-selective installation of a glycoside bond at only the ketone or at only the alcohol is possible based on catalyst structure without separate steps involving the protection and deprotection of the alcohol functionality. Additionally, generation of a new stereogenic center, subject to substrate-controlled diastereoselection, is possible during the hydrosilylationglycosylation sequence, thus allowing aglycone tailoring and glycoside bond installation to be 
accomplished in a single strategy. We anticipate that these advances will facilitate the rapid synthesis of various classes of synthetic and natural product-derived glycoconjugates. Application of this concept to other catalytic processes involving sugar silanes, including C$\mathrm{C}$ bond-forming processes, is in progress.

\section{Experimental Section}

General Procedure for the $\mathrm{Ni}(\mathrm{COD})_{2} / \mathrm{IMes}$ Promoted Hydrosilylation of Ketones: A solid mixture of $\mathrm{Ni}(\mathrm{COD})_{2}(10 \%)$, IMes. $\mathrm{HCl}(10 \%)$, and KO- $t \mathrm{Bu}(10 \%)$ was dissolved in dry THF $(0.02 \mathrm{M})$ at $\mathrm{rt}$ under an inert atmoshphere $\left(\mathrm{N}_{2}\right)$, and stirred for $10-15$ minutes until the catalyst mixture was a dark blue color. $\mathrm{Ti}(\mathrm{O}-\mathrm{iPr})_{4}(1.1-2.2$ equiv $)$ was then added to the catalyst mixture followed by the addition of the sugar silane (1.1 equiv), and ketone (1.0 equiv) as a solution in dry THF $(0.2 \mathrm{M})$. Upon completion of the reaction, as monitored by TLC, the reaction mixture was filtered through a short plug of silica gel with a mixture of EtOAc/hexanes and concentrated by rotary evaporation. The resulting residue was purified via flash chromatography $\left(\mathrm{SiO}_{2}\right)$ to afford the desired product. Note - When doing the site-selective hydrosilylation of a ketone in the presense of a free hydroxyl group, the use of 2.2 equiv of $\operatorname{Ti}(\mathrm{O}-i \mathrm{Pr})_{4}$, and a $0.05 \mathrm{M}$ solution in THF results in higher yields of the desired product.

General Procedure for the $\mathrm{CuCl} / \mathrm{IMes}$ Promoted Hydrosilylation of Ketones: A solid mixture of $\mathrm{CuCl}(5 \%)$, IMes. $\mathrm{HCl}(5 \%)$ and $\mathrm{KO}-\mathrm{tBu}(10 \%)$ was dissolved in dry toluene $(0.015 \mathrm{M})$ at $\mathrm{rt}$ under an inert atmosphere $\left(\mathrm{N}_{2}\right)$, and stirred for 20 minutes. A mixture of ketone (1.0 equiv) and silane (1.1 equiv) was dissolved in dry toluene $(0.2 \mathrm{M})$, the catalyst was then added to this mixture as a solution in a minimum of dry toluene. Upon completion of the reaction, as monitored by TLC, the reaction mixture was filtered through a short plug of silical gel with a mixture of EtOAc/hexanes and concentrated by rotary evaporation. The resulting residue was purified via flash chromatography $\left(\mathrm{SiO}_{2}\right)$ to afford the desired product.

\section{Supplementary Material}

Refer to Web version on PubMed Central for supplementary material.

\section{Acknowledgments}

The authors wish to acknowledge support from the National Institutes of Health (GM 57014) and from Thermo Fisher for a pilot project grant administered by the University of Michigan Life Sciences Institute.

\section{References}

1. (a) Wong, C-H., editor. Carbohydrate-Based Drug Discovery. Vol. 1. Wiley; Weinheim: 2003. Klyosov, AA.; Witczak, ZJ.; Platt, D., editors. Carbohydrate Drug Design; ACS Symposium Series 932; Washington, DC: American Chemical Society; 2006. (c) Galonic DP, Gin DY. Nature 2007;446:1000-1007. [PubMed: 17460660] (d) Pratt MR, Bertozzi CR. Chem Soc Rev 2005;34:5868. [PubMed: 15643490] (e) Herzner H, Reipen T, Schultz M, Kunz H. Chem Rev 2000;100:44954538. [PubMed: 11749356] (f) Buskas T, Ingale S, Boons GJ. Glycobiology 2006;16:113R-136R. (g) Borman S. Chem Eng News September 4;2006 84:17-26.

2. For reviews: (a) Toshima K, Tatsuta K. Chem Rev 1993;93:1503-1531. (b) Cumpstey I. Carbohydrate Res 2008;343:1553-1573. For representative state-of-the-art glycosylation methods: (c) Kahne D, Walker S, Cheng Y, Van Engen D. J Am Chem Soc 1989;111:6881-6882. (d) Crich D, Sun S. J Am Chem Soc 1997;119:11217-11223. (e) Mootoo DR, Konradsson P, Udodong U, Fraser-Reid B. J Am Chem Soc 1988;110:5583-5584. (f) Schmidt RR, Michel J. Angew Chem Int Ed Engl 1980;19:731732. (g) Mukaiyama T, Murai Y, Shoda SI. Chem Lett 1981:431-432. (h) Plante OJ, Palmacci ER, Seeberger PH. Science 2001;291:1523-1527. [PubMed: 11222853]

3. (a) Friesen RW, Danishefsky SJ. J Am Chem Soc 1989;111:6656-6660. (b) Halcomb RL, Danishefsky SJ. J Am Chem Soc 1989;111:6661-6666. 
4. (a) Jung KH, Müller M, Schmidt RR. Chem Rev 2000;100:4423-4442. [PubMed: 11749353] (b) Zhu X, Schmidt RR. Angew Chem Int Ed 2009;48:1900-1934. (c) Fairbanks AJ. Synlett 2003:1945. (d) Cumpstey I. Carb Res 2008;343:1553.

5. Barresi F, Hindsgaul O. J Am Chem Soc 1991;113:9376-9377.

6. Ito Y, Ogawa T. Angew Chem 1994;33:1765-1767.

7. (a) Stork G, Kim G. J Am Chem Soc 1992;114:1087-1088. (b) Stork G, La Clair JJ. J Am Chem Soc 1996;118:247-248.

8. (a) Bols M. J Chem Soc, Chem Commun 1992:913-914. (b) Bols M. Tetrahedron 1993;49:10049_ 10060. (c) Bols M. J Chem Soc, Chem Commun 1993:791-792. (d) Bols M, Hansen HC. Chem Lett 1994:1049-1052.

9. (a) Schmidt RR. Angew Chem Int Ed 1986;25:212-235. (b) Ryan DA, Gin DY. J Am Chem Soc 2008;130:15228-15229. [PubMed: 18950157]

10. We use the term "orthogonal" to refer to the glyosyl acceptor. Orthogonal glycosyl donors have previously been described: Kanie O, Ito Y, Ogawa T. J Am Chem Soc 1994;116:12073.

11. (a) Callam CS, Lowary TL. J Org Chem 2001;66:8961-8972. [PubMed: 11749629] (b) Bamhaoud T, Sanchez S, Prandi J. Chem Commun 2000:659-670. (c) Düffel A, Green LG, Ley SV, Miller AD. Chem Eur J 2000;6:1416-1430.

12. (a) Irrgang T, Schareina T, Kempe R. J Mol Cat A: Chem 2006;257:48-52. (b) Kong YK, Kim J, Choi S, Choi SB. Tetrahedron Lett 2007;48:2033-2036. (c) Chaulagain MR, Mahandru GM, Montgomery J. Tetrahedron 2006;62:7560-7566.

13. (a) Díez-González S, Nolan SP. Acc Chem Res 2008;41:349-358. [PubMed: 18281951] (b) Kaur H, Zinn FK, Stevens ED, Nolan SP. Organomet 2004;23:1157-1160. (c) Díez-González S, Kaur H, Zinn FK, Stevens ED, Nolan SP. J Org Chem 2005;70:4784-4796. [PubMed: 15932319] See also: (d) Lipshutz BH, Chrisman W, Noson K. J Organomet Chem 2001;624:367-371.

14. (a) Ennis SC, Fairbanks AJ, Tennant-Eyles RJ, Yeates HS. Synlett 1999:1387. (b) Fügedi P, Garegg PJ, Lönn H, Norberg T. Glycoconjugate J 1987;4:97. (c) Veeneman GH, van Leeuwen SH, van Boom JH. Tetrahedron Lett 1990;31:1331-1334. (d) Konradsson P, Ododong UE, Fraser-Reid B. Tetrahedron Lett 1990;31:4313-4316. (e) Zhu T, Boons GJ. Org Lett 2001;3:4201-4203. [PubMed: 11784177] (f) Geurtsen R, Coté F, Hahn MG, Boons GJ. J Org Chem 1999;64:7828-7835.

15. Synthesis of C-glycosides via coupling processes starting with ketones is well precedented: (a) Miquel N, Doisneau G, Beau JM. Angew Chem Int Ed 2000;39:4111-4114. (b) Miquel N, Doisneau G, Beau JM. Chem Commun 2000:2347-2348. (c) Brunckova J, Crich D. Tetrahedron 1995;51:1194511952. (d) Herrera AJ, Rondón M, Suárez E. Synlett 2007:1851-1856. (e) Herrera AJ, Rondón M, Suárez E. J Org Chem 2008;73:3384-3391. [PubMed: 18370422]

16. Using acetone or cyclohexanone as solvent, acetal-linked glycosides have been prepared: Aloui M, Fairbanks AJ. Chem Commun 2001:1406-1407.

17. For a discussion of protecting group-free synthesis: Baran PS, Maimone TJ, Richter JM. Nature 2007;446:404-408. [PubMed: 17377577]

18. For an example of catalyst-controlled site-selective polyol derivatization: Lewis CA, Miller SJ. Angew Chem Int Ed 2006;45:5616-5619.

19. (a) Lorenz C, Schubert U. Chem Ber 1995;128:1267-1269. (b) Schmidt DR, O’Malle SJ, Leighton JL. J Am Chem Soc 2003;125:1190-1191. [PubMed: 12553820]

20. For other nickel-catalyzed processes involving silanes that tolerate unprotected hydroxyls: (a) Mahandru GM, Liu G, Montgomery J. J Am Chem Soc 2004;126:3698-3699. [PubMed: 15038707] (b) Herath A, Montgomery J. J Am Chem Soc 2008;130:8132-8133. [PubMed: 18540581]

21. The reversal of selectivity is not due solely to the presence of $\mathrm{Ti}(\mathrm{O}-i \mathrm{Pr})_{4}$ in the nickel-catalyzed procedure. Adding this reagent to the copper protocol led only to the corresponding isopropoxy sugar silane. 


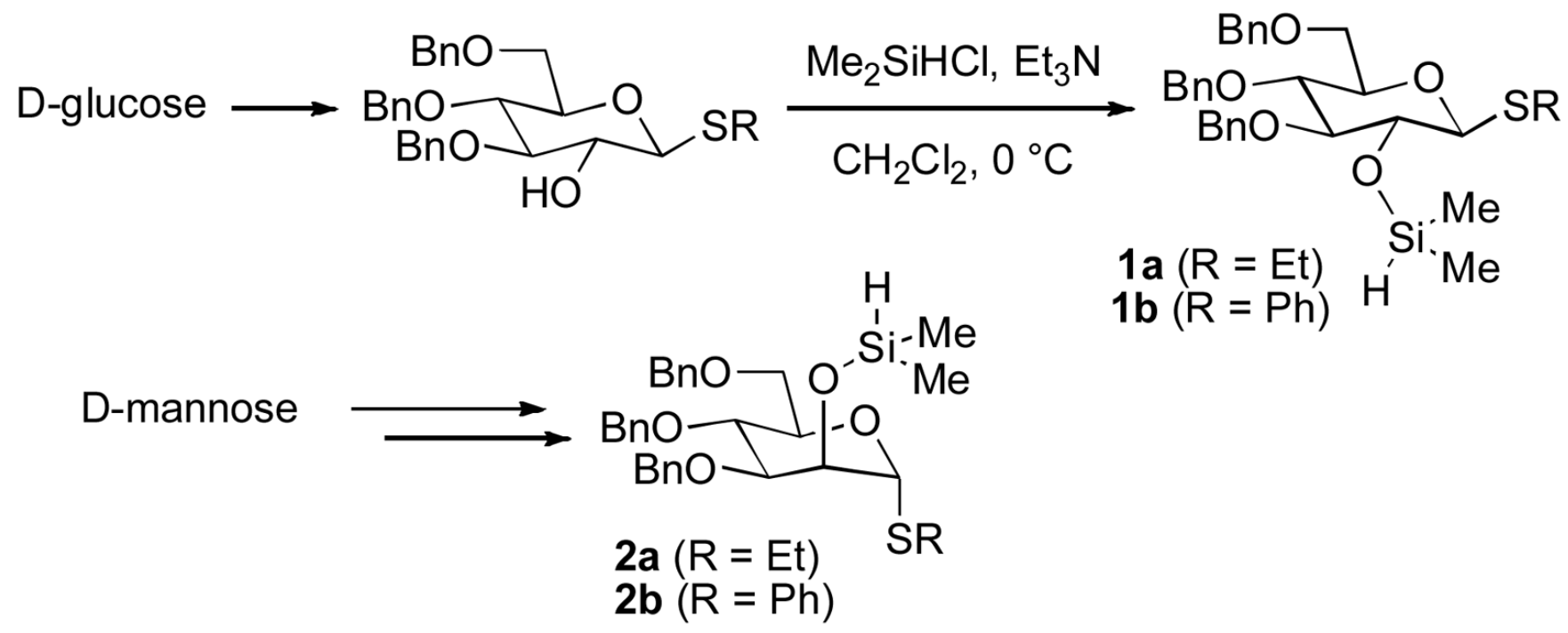

Scheme 1.

Preparation of Sugar Silane Reagents 


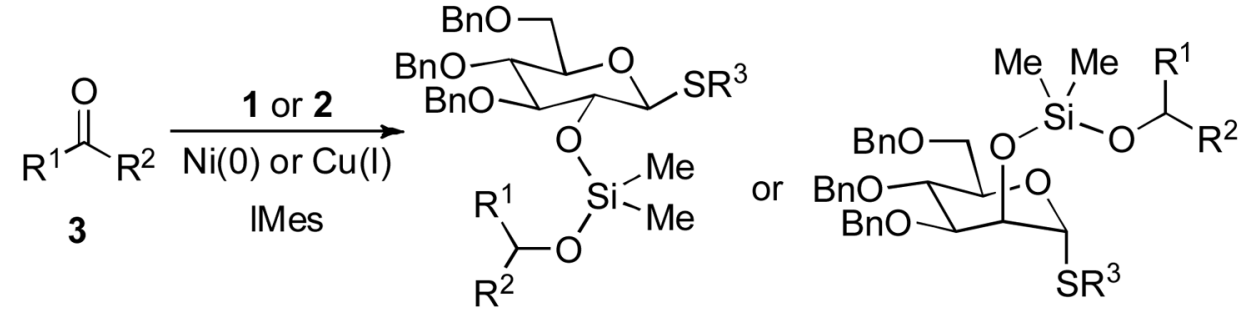

4 (from 1a or 1b)

5 (from $2 a$ or $\mathbf{2 b}$ )

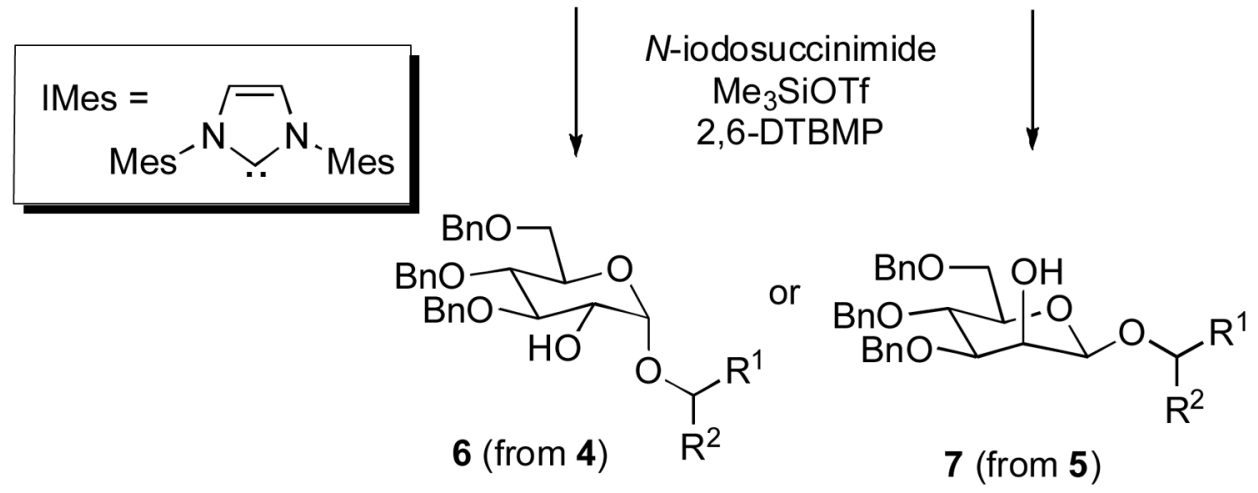

Scheme 2.

Strategy for Conversion of Ketones to Glycosides. 


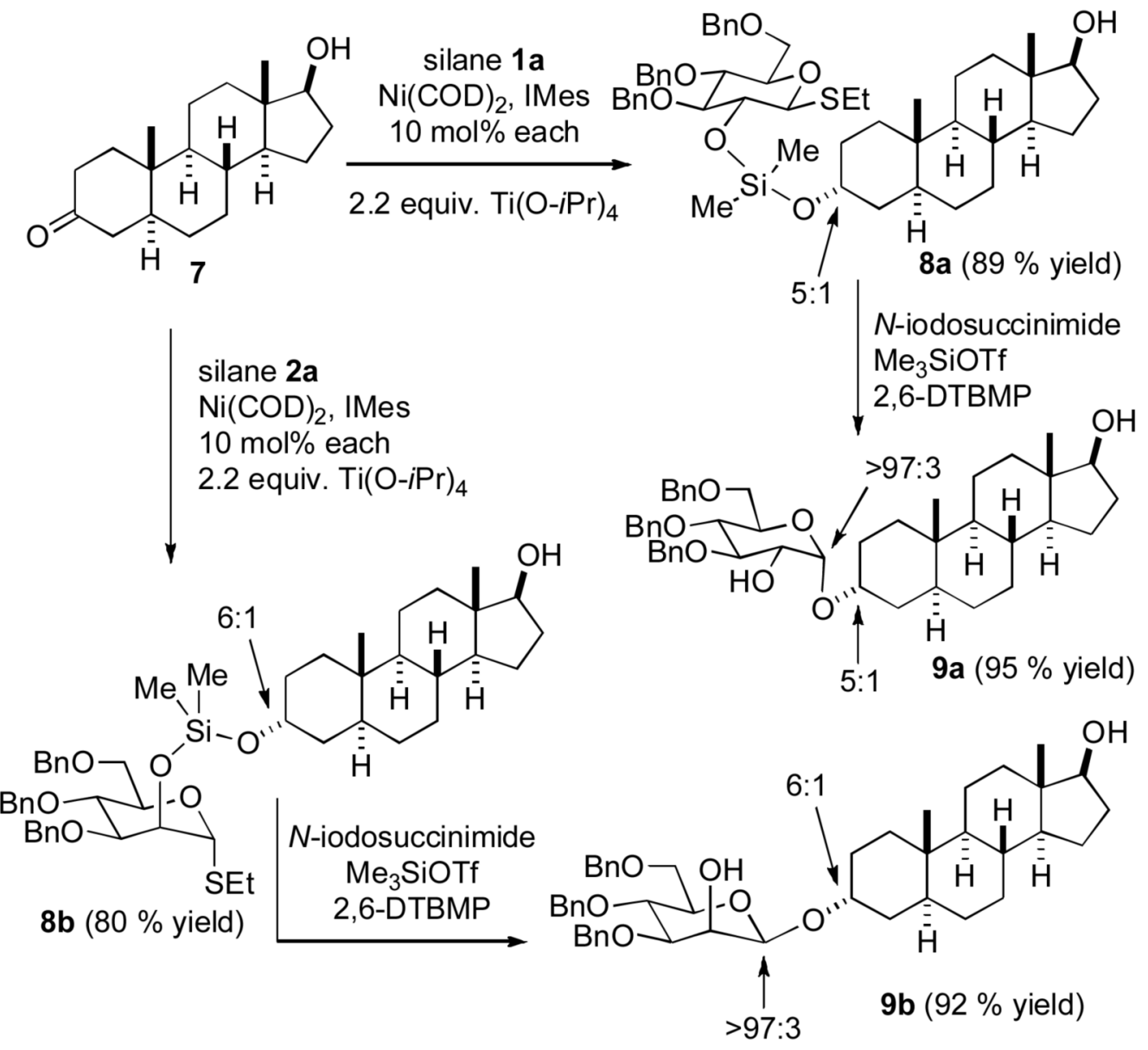

Scheme 3.

Hydroxyketone Site-selective Glycosylation. 

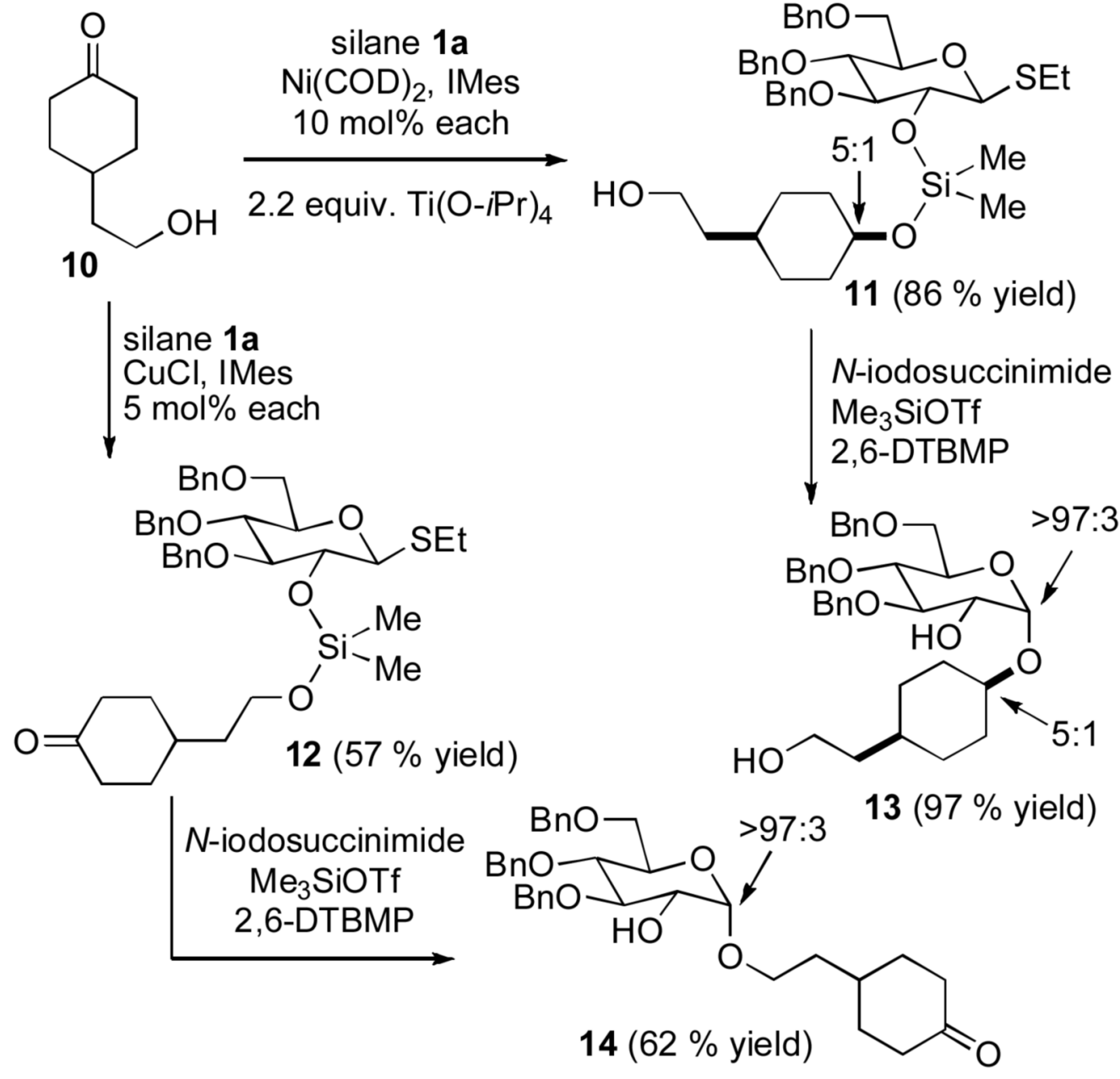

Scheme 4.

Catalyst-Controlled Site Reversal. 
Table 1

Ketone Glycosylations.

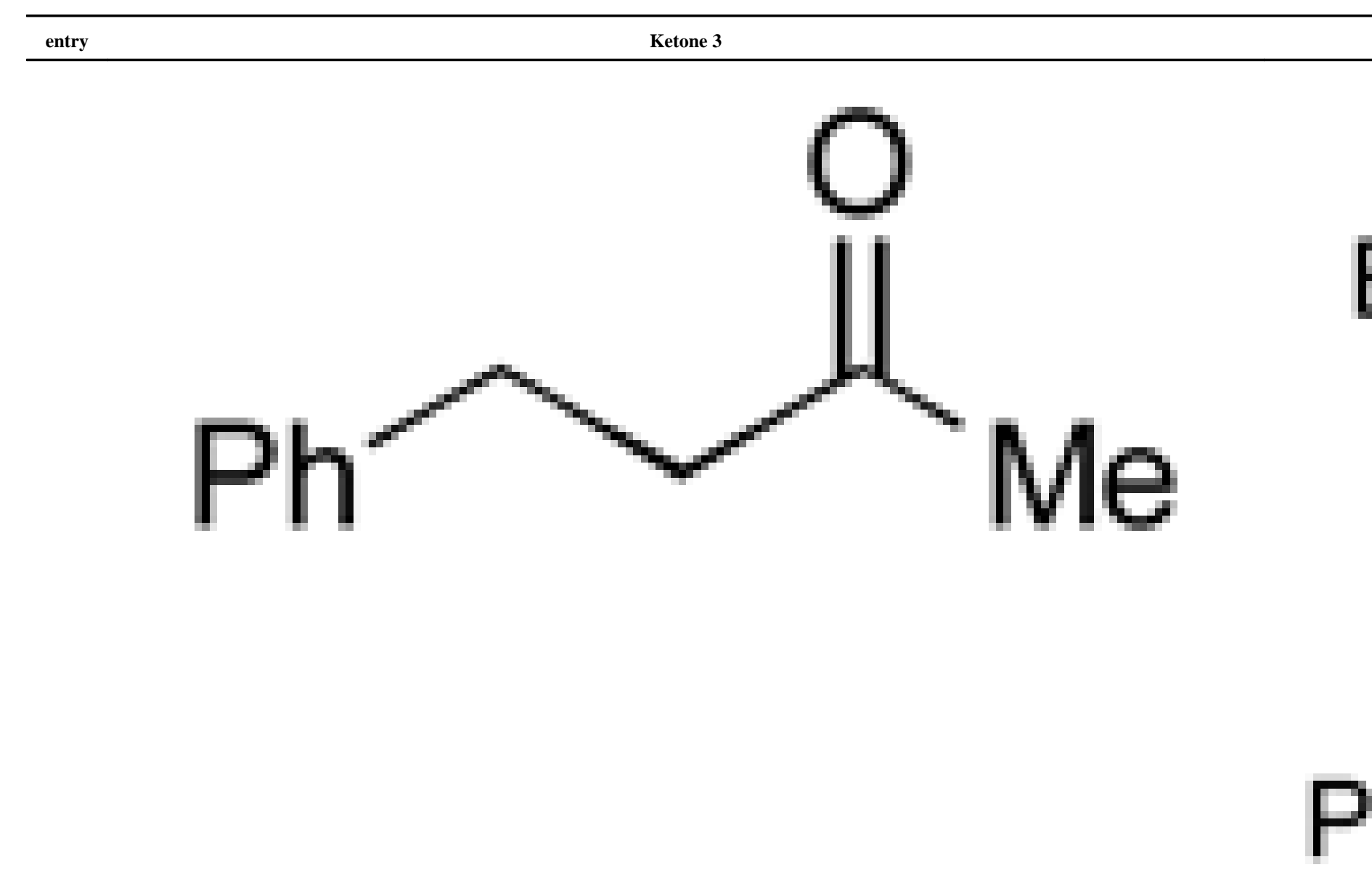


$\begin{array}{ll}\text { entry } & \text { Ketone } 3\end{array}$

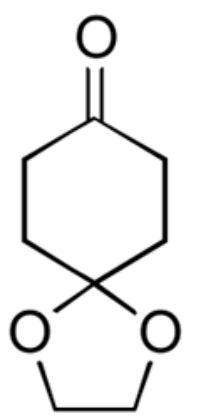


\begin{tabular}{ll}
\hline entry & Ketone 3 \\
\hline
\end{tabular}

Ketone 3
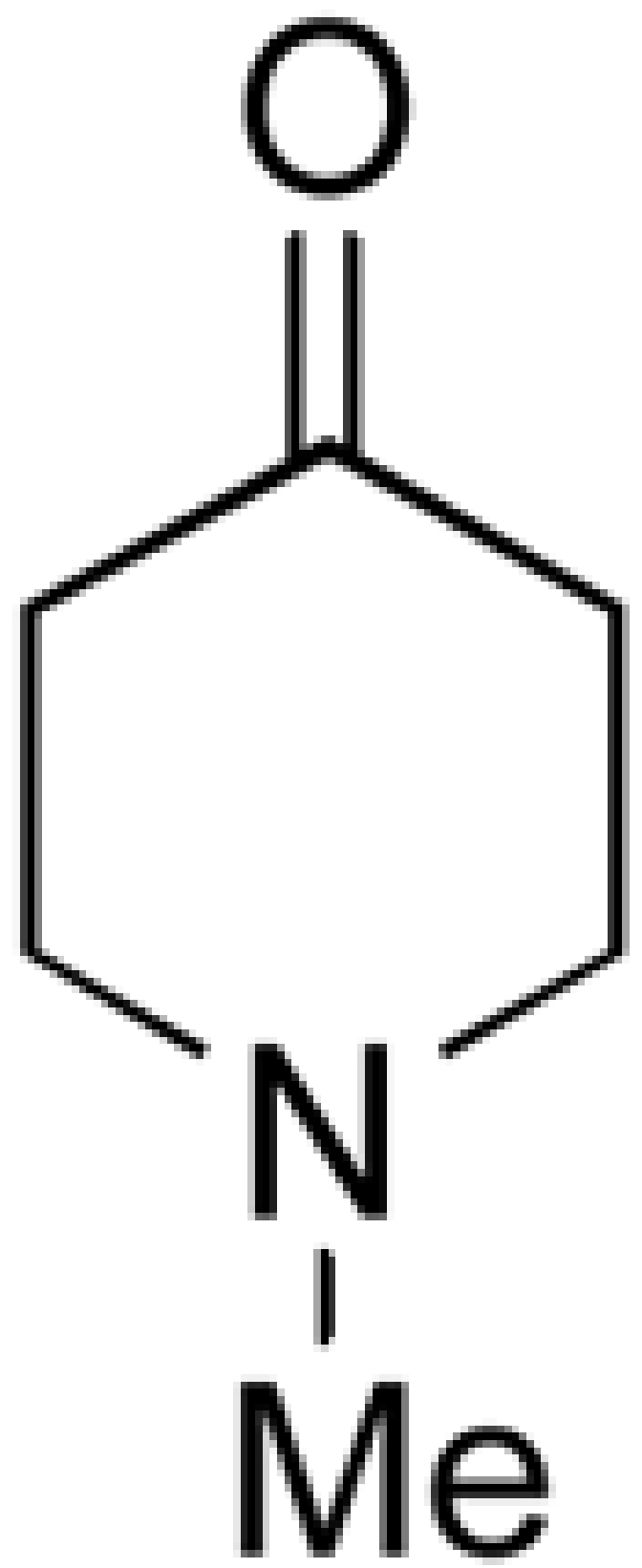

3

$3 c$ 
\begin{tabular}{ll}
\hline entry & Ketone 3 \\
\hline
\end{tabular}

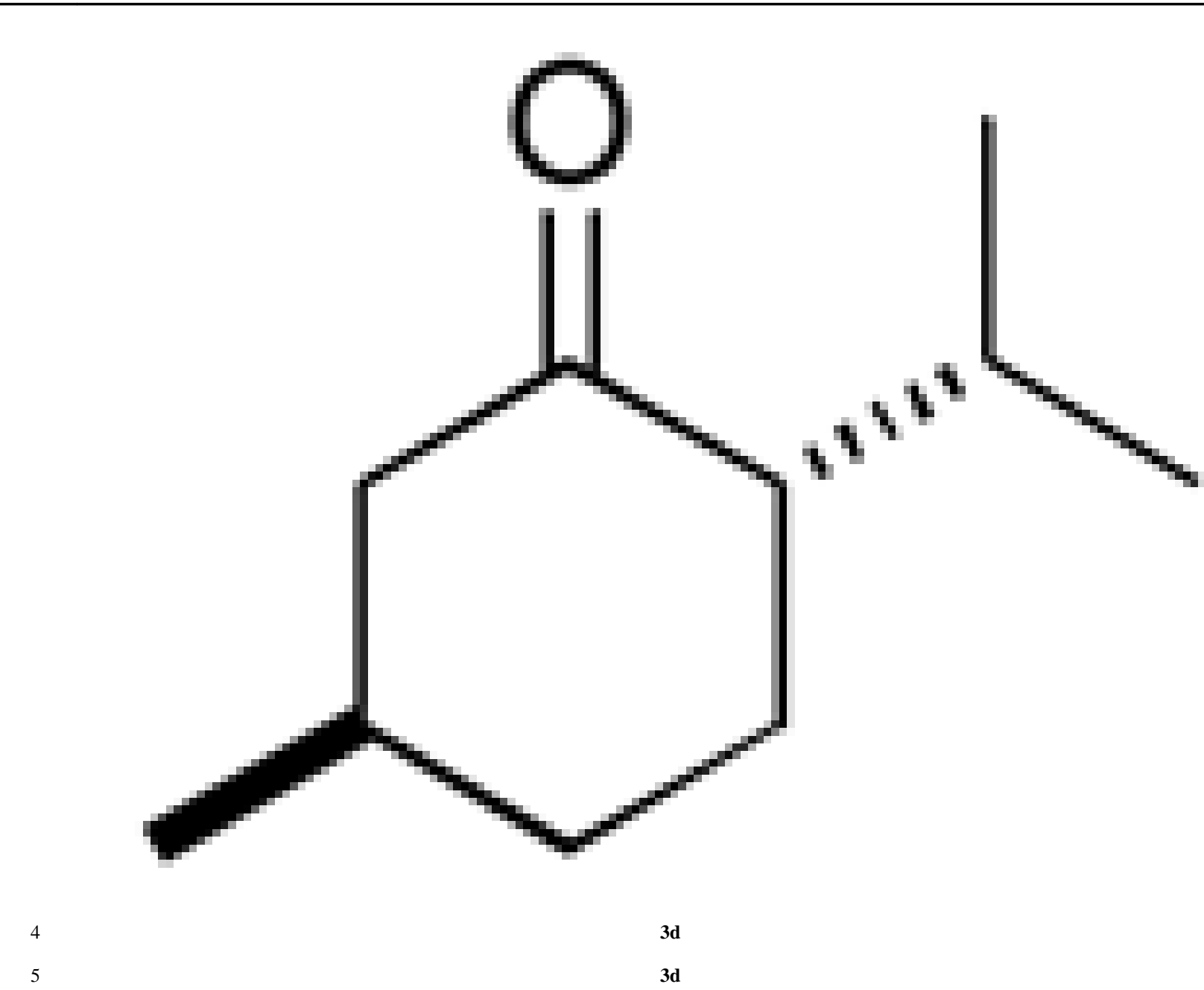


${ }^{a}$ Method A was employed: $\mathrm{Ni}(\mathrm{COD}) 2(10 \mathrm{~mol} \%)$, IMes $\mathrm{HCl}(10 \mathrm{~mol} \%), \mathrm{KO}-\mathrm{tBu}(10 \mathrm{~mol} \%)$, Ti(O-iPr)4 (1.1 equiv), silane 1 or 2 (1.1 equiv), ketone (1.0 equiv), THF (0.1 M), rt, 3-13 h.

${ }^{b}$ Method B was employed: $\mathrm{CuCl}$ (5 mol \%), IMes. $\mathrm{HCl}(5 \mathrm{~mol} \%), \mathrm{NaO}-t \mathrm{Bu}(10 \mathrm{~mol} \%)$, silane 1 or 2 (1.1 equiv), ketone (1.0 equiv), toluene (0.12 M), rt, 4-8 h.

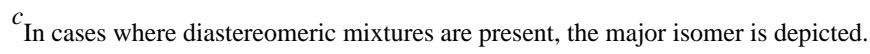

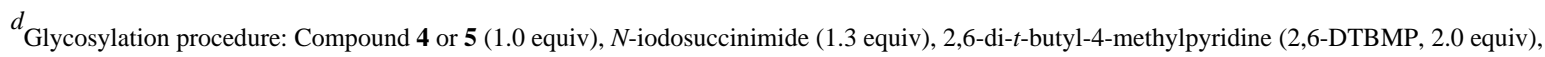
trimethylsilyl triflate (1.2 equiv), $\mathrm{CH}_{2} \mathrm{Cl}_{2},-40$ to $0{ }^{\circ} \mathrm{C}$, then $n \mathrm{Bu} 4 \mathrm{NF}$. 